\title{
FERNÁNDEZ DE LIZARDI Y CERVANTES
}

Se recuerda a Joaquín Fernández de Lizardi especialmente por su Periquillo Sarniento (1816), obra que hizo historia como la primera novela hispanoamericana. Curiosamente, la crítica se refiere sólo de paso a la influencia de Cervantes en Lizardi, como por ejemplo el mexicano Ignacio Altamirano, uno de los primeros en referirse a esa influencia. Pero Alfonso Reyes, en su resumen de la crítica literaria sobre el Periquillo, considera inexplicable que los críticos hayan mencionado esa afinidad ${ }^{1}$. En mi opinión, y a pesar de las diferencias que existen entre las novelas cervantinas y las del escritor mexicano, una lectura atenta de las tres novelas ${ }^{2}$ de Lizardi nos llevaría a dudar un poco del juicio categórico de Alfonso Reyes.

La intención fundamental de Cervantes era fundir elementos de las novelas de caballerías, de la pastoril, de la picaresca, de la crónica y de las teorías literarias de su época ${ }^{3}$. El Periquillo de Lizardi fue casi un accidente histórico: la censura de prensa le había obligado a suspender la publicación de su periódico didáctico El Pensador Mexicano y a buscar un medio menos estridente para expresar sus opiniones ${ }^{4}$. Con todo, el Periquillo es una muestra excelente de las ideas de la Ilustración que dominaban en la época y que pueden faltar en las otras obras de Lizardi: fábulas, versos satíricos, dos novelas más, seis obras de teatro, alrededor de trescientos cincuenta folletos ${ }^{5}$, y en los periódicos que él editaba. Esta obra numerosa se escribió en un período de dieciséis años (1811-1827), que coincide, en lo general, con las guerras de Independencia.

1 ALFONSO REYES, "El Periquillo Sarniento y la crítica mexicana", Obras completas, t. 4, México, 1956, p. 170. Véase ahora la tesis doctoral de JOHN PAWLOWSKI, The novels of Fernández de Lizardi, Northwestern University, 1972, pp. 271-273, quien dedica unas cuantas páginas a los elementos comunes entre el Quijote y las novelas de Lizardi. El tema se trata superficialmente en ARNOLD C. VENTO, "El Periquillo y el Quijote", UMx, 1965, núm. 12, pp. 13-15.

2 Noches tristes $y$ dia alegre, a menudo citada como la cuarta novela de Lizardi, se excluye aquí, porque está casi totalmente en forma de diálogo. En este sentido es similar al Coloquio de los perros de Cervantes o a Noches lúgubres de José Cadalso.

3 E. C. RILEY, Cervantes's theory of the novel, London, 1964. Véanse pp. 1-13 sobre Cervantes y la teoría literaria de su época.

4 JEFFERSON REA SPELL, The life and works of José Joaquin Fernández de Lizardi, Philadelphia, 1931, p. 31.

5 El número de trescientos cincuenta folletos supera los estimados anteriores; véase ROBERT KARL FRITZ, The attitude of José Joaquin Fernández de Lizardi ("El Pensador 


\section{DE LA CRÍTICA LITERARIA SOBRE LIZARDI}

Hay acuerdo general en que la preocupación de Lizardi por la didáctica debilita sus creaciones literarias desde el punto de vista estético. Alfonso Reyes hace eco a una larga historia de crítica literaria al comparar el Periquillo Sarniento con Guzmán de Alfarache, especialmente en la tendencia común a divagar sermoneando, pero concluye que la novela mexicana es inferior a su paradigma español porque Lizardi sacrifica el arte a sus sermones (op. cit., p. 170). Otra diferencia notable es el optimismo de Lizardi en lo referente al progreso, heredado de la Ilustración, en contraste con el tono pesimista del Guzmán. Al relatar la historia de su vida, Periquillo aconseja a sus hijos que aprendan de sus errores; dice, en otras palabras, que el hombre puede mejorar a través de la educación.

Jefferson Rea Spell opina que el Periquillo, en su época, era "básicamente una obra de propaganda" 6 , y en general considera que Lizardi "utilizó su habilidad para manejar las palabras -habilidad de la cual él mismo estaba muy consciente- para un solo fin: reformar. Nunca buscó hacer literatura como tal" ${ }^{7}$. Nos preguntamos si nuestra sociedad necesita las mismas reformas que la de Lizardi, si el lector contemporáneo podría beneficiarse con algo de moralismo, o si un lector que desconoce la historia de México puede apreciar las obras de Lizardi simplemente como literatura. Una respuesta puede ser la traducción del Periquillo de Katharine Anne Porter, quien corta muchas de las divagaciones para dejar el esqueleto de un relato picaresco muy divertido. Justifica su cirugía como una forma de modemización: "at last the story has been stripped of its inmense accumulation of political pamphlets and moral disquisitions, which served their purpose once, let us hope, as the author ment them" 8 .

Algunas de las críticas de Lizardi, válidas en ciertos contextos culturales, pudieron habérsele escapado a Katharine Anne Porter, y algunas de sus metas y reformas (educación escolástica, las evidentes distinciones de clase entre el rico ocioso y el igualmente ocioso pordiosero, la ley del primogénito, la explotación al indio) pueden ser todavía problemas reales en algunos países latinoamericanos, aunque en América hispánica la herencia colonial haya desaparecido en gran medida. En realidad, para los curiosos de la historia, la obra de Lizardi es una ventana abierta al pasado. No tanto en sus novelas escritas durante un período de censura severa en las que los temas políticos específicos

Mexicano") toward Mexican independence from Spain, tesis, Indiana University, 1975, pp. 12 y 21 , nota 13.

6 JEFFERSON REA SPELL, Bridging the gap: Articles on Mexican literature selected from the works of: .., México, 1972, p. 171.

7 Ibid., p. 81.

8 The Itching Parrot. El Pcriquillo Sarniento, tr. and introd. by K. A. Porter, Doubleday, 1942 , p. vii. 
de la época quedaron fuera, sino en sus folletos que tienen un público más limitado porque deben leerse dentro del contexto histórico.

Al escribir el Periquillo, Lizardi se inspira en la máxima de Horacio: "De escritor el oficio desempeña, quien divierte al lector y quien le enseña" ". Si bien el Periquillo ofrece una mezcla de entretenimiento y enseñanza, estos dos extremos del propósito del autor parecen estar separados en sus otras dos novelas. La Quijotita y su prima (18181819) es una novela engorrosa con una tesis sobre la educación de las mujeres, que carece de verosimilitud. El crítico mexicano, Carlos González Peña, se atreve a llamarla "el más abominable sermón de que las letras nacionales tienen memoria" ${ }^{10}$. Sin embargo, puede resultar interesante para algunos lectores como un débil precursor del feminismo. M. del C. Ruiz Castañeda opina que el examen de las virtudes y defectos de las mujeres en la novela "conserva interés y encanto para el lector moderno" "1.

Mucho más divertida que un tratado de pedagogía es Don Catrín de la Fachenda (1832). Anderson Imbert considera que ésta es la mayor obra de Lizardi, precisamente por su maestría para relatar una historia desprovista de divagaciones ${ }^{12}$. El mismo Lizardi podría haber estado de acuerdo. EI narrador de Don Catrín está muy consciente de los errores del Periquillo como lo hacen notar los críticos contemporáneos de la primera novela. Lizardi está resuel to a mejorar: "[ mi obra], descargada de episodios inoportunos, de digresiones fastidiosas, de moralidades cansadas, y reducidas a un solo tomito en octavo, se hará desde luego más apreciable y legible" ${ }^{13}$. Don Catrín puede ser una lectura más entretenida y una mejor novela picaresca, pero le falta la riqueza del Periquillo como mosaico social, como documento lingüístico y como epítome de las ideas de la Ilustración en su época.

A pesar de todo su valor histórico, el Periquillo no es una novela histórica, como creía Francisco Pimentel (crítico del siglo xix), quien sugiere que el Periquillo es a la historia colonial mexicana lo que las novelas históricas de Walter Scott son a la Edad Media ${ }^{14}$. Fernández de Lizardi vivió los últimos días de la sociedad colonial y la criticó, no como un romántico, sino como un ilustrado y un precursor del realismo costumbrista. Scott, al contrario, imaginó románticamente el pasado medieval a siglos de distancia.

¿Con quien podría compararse el protagonista del Periquillo? Jaime Torres Bodet encuentra en el personaje un tipo nacional para México,

9 El Periquillo Sarniento, $15^{\mathrm{a}}$ ed., Porrúa, México, 1976, p. 41. En adelante cito por esta edición.

10 "El Pensador Mexicano y su tiempo", Conferencias del Ateneo de la Juventud, México, D. F., Imprenta Lacaud, 1910 , p. 102.

11 Véase su introducción a La Quijotita y su prima, México, 1967, p. xii.

12 Historia de la literatura hispanoamericana, t. 1, México, 1962, p. 187.

13 Vida y hechos del famoso caballero Don Catrín de la Fachenda. Obra inédita del Pensador Mexicano, $1^{\text {il }}$ ed., Imprenta del Ciudadano Alejandro Valdés, México, 1832, p. 4. En adelante cito por esta edición.

14 ALFONSO REYES, op. cit., p. 177. 
como Babbitt para Estados Unidos y Martín Fierro o don Segundo Sombra para Argentina ${ }^{15}$. El hombre de negocios de Lewis y el gaucho de José Hernández son herramientas de crítica social, como Periquillo, pero ¿cuántos mexicanos aceptarían al pícaro criollo de pocos escrúpulos y sin ninguna habilidad práctica como la suma del carácter nacional? Lo mismo podría decirse de Babbitt o de Martín Fierro, quienes también llevan algo de la aureola del héroe épico. Por lo menos, Babbitt y Martín Fierro desempeñan sus papeles convincentemente. Aunque Lizardi describe con detalle el ambiente realista de la sociedad mexicana (comidas, muebles, costumbres, actitudes, diversiones), no logra crear personajes convincentes con profundidad psicológica. ¿Sacrificó lo uno por lo otro? La gran verosimilitud de Don Catrín como un pillo degenerado, en una novela con menos divagaciones y menos detalles, me lleva a pensar que así es. Sin embargo, el Quijote es una novela llena de divagaciones y detalles, y pocos cuestionarían la verosimilitud de Don Quijote y Sancho Panza.

\section{ELEMENTOS CERVANTINOS EN LiZARDI}

En la crítica contemporánea del Periquillo Sarniento encontramos un comentario que provocó una "apología cervantina" (la autodefensa de Lizardi invocando el modelo de Cervantes). El señor "Ranet" (anagrama de Terán, an tiguo enemigo de Lizardi) escribió del Periquillo que no era artístico describir a "las peores gentes de la sociedad" actuando y hablando en forma ordinaria. El comentario, obviamente, se refería a la abundancia de dichos populares, expresiones idiomáticas y argot que usa Lizardi para conseguir un retrato realista de todos los niveles de la sociedad mexicana. Lizardi contestó que no veía en el Quijote de Cervantes "nada raro, nada extraordinario, nada prodigioso. Todos los sucesos son demasiado vulgares y comunes, tales como pudieran acontecer a un loco de las circunstancias de don Alonso Quijada. Al mismo tiempo advierto que cada uno de los personajes de la fábula habla como los de su clase, esto es, vulgar y comúnmente. Hasta hoy estaba yo entendido en que una de las gracias de este género de composición era corregir las costumbres rediculizándolas y pintándolas al natural, según el país donde se escribe" 16 .

"Ranet" critica también la severa moral de Lizardi en la novela. En respuesta, Lizardi expresa su temor de que los lectores se contentaran con leer novelas simplemente como entretenimiento, y que muchos lectores necesitaban comentarios adicionales para entender el Quijote, Gil Blas de Santillana y otras obras, si habían de ir más allá

15 "Estudio preliminar a José Joaquín Fernández de Lizardi", El Pensador Mexicano, México, 1962, p. vii.

16 "Apología del Periquillo Sarniento, Artículo inserto. . de 12 a 15 de febrero de 1819 del Noticioso General", en José Joaquín Fernández de Lizardi [El Pensador Mexicano], El Periquillo Sarniento, Barcelona, 1933, p. 6. 
del nivel del entretenimiento. Lizardi admite que está rompiendo conscientemente una regla del arte al moralizar sobre la acción del Periquillo, "estoy persuadido de que los lectores para quienes escribo necesitan, ordinariamente, que se les den las moralidades mascadas y aun remolidas, para que les tomen el sabor y las puedan pasar, si no saltan sobre ellas con más ligereza que un venado sobre las hierbas del campo" 7 .

La ficción es para Lizardi una forma conveniente para atraer al público renuente a escuchar un sermón. Al final de la novela hay un juicio similar: al discutir los méritos de la obra con la viuda del Periquillo, "El Pensador Mexicano" comenta que esa autobiografía es como "las píldoras que se doran" para ayudar a pasar la medicina (esto es el didactismo). Añade que entre los elementos que la hacen accesible a un público amplio están el sentido del humor y "un estilo casero y familiar" (p. 463).

En su "apología cervantina", Lizardi continúa defendiendo su didacticismo señalando que Don Quijote también tenía facilidad para moralizar (p. 41). Ésta es una de esas pocas veces en que el autor hace comentarios favorables sobre la personalidad de Don Quijote, ya que generalmente tiene una visión muy propia del siglo XVIII, de un loco cuyas ambiciones son disparates ridículos sin valor redentor. Los racionalistas de la Ilustración en general no pudieron ver el admirable idealismo de Don Quijote que reivindicarían los románticos del siglo $\mathrm{XIX}^{18}$. En este aspecto, como en muchos otros, Lizardi está más cerca de la Ilustración que del romanticismo.

Cuando el Periquillo recuerda haber tenido alguna vez delirios de ser un virrey y un noble, se refiere a sí mismo como "el nuevo Quijote" por sus "locuras caballerescas" (p. 357). Similar actitud revela Lizardi en un folleto en el cual aparece un diálogo sobre la concesión de escudos de armas (títulos de nobleza) a los soldados valientes de la guerra de independencia a base del mérito, no de linaje. Cuando uno de los mexicanos objeta que esto va en contra de la tradición española, otro, probablemente hablando por Lizardi, concluye que "esas son las preocupaciones de la rancia España, y por las que el famoso Cervantes escribió su tan bien aplaudido Quijote" ${ }^{\prime 9}$. En otras palabras, Lizardi interpreta el Quijote como una crítica a la hidalguía de la época y como una parodia de la caballería andante. En un poema satírico, Lizardi se burla de las pretensiones de un rico caballero, "con el ruido del dinero, se dice que es caballero, /díganle que es un Quixote/ y acocote" ${ }^{20}$. Aumenta el humor el ritmo truncado de acocote,

${ }^{17}$ Ibid., p. 8.

${ }^{18}$ Raimundo Lida, Course lectures at Harvard University, diciembre 14 y 16,1970

${ }^{19}$ Lizardi, Las tertulias de los muertos antiguos y modernos por El Pensador Mexicano, México. En la imprenta de D. Celestino de la Torre, 1821, p. 3.

${ }^{20}$ Ratos entretenidos, o miscelánea útil y curiosa, compuesta de varias piezas ya impresas, México, 1819, reimpreso en la oficina de D. Alexandro Valdés, t. 1, p. 159 
un mexicanismo para una calabaza larga, y es todavía más humorístico en el contexto del refrán mexicano citado antes en el poema: "El que de chico es guaje [calabazo; tonto] hasta acocote no para" ${ }^{21}$.

Fernández de Lizardi parodia la retórica elevada del Quijote para satirizar a sus oponentes políticos por su falso sentido de la importancia ${ }^{22}$; y para poner en evidencia el hecho de que Don Quijote no alcanza su ideal de generosidad, compara el caso de la visita de unos inspectores de cárceles en el México colonial con Don Quijote cuando libera a Andrés de su castigo cruel: los inspectores, genuinamente preocupados, dejarán las cárceles, después de lo cual los guardias intensificarán el castigo, exactamente como el amo de Andrés ${ }^{23}$. Lizardi escoge uno de los menos halagüeños episodios del Quijote, para convencernos de que la caballerosidad y nobleza de Don Quijote son ilusorias.

El caso más claro de influencia cervantina se encuentra en La Quijotita y su prima: Sansón Carrasco (nombre del personaje cervantino que considera a Don Quijote más loco que noble) da a Pomposa el sobrenombre de "Quijotita". De la misma manera que la imaginación de Don Quijote se desboca después de haber leído tantos libros de caballería, así también Pomposa concibe la fantasía de ser la mujer más hermosa, más perfecta del mundo, que debe reivindicar a su sexo conquistando psicológicamente la adoración de todos los hombres. Sansón Carrasco explica las razones para su sobrenombre: tanto Don Quijote como Doña Pomposa están locos por sus ambiciones: "Don Quijote siempre esperaba llegar a ser emperador a costa de la fuerza de su brazo; Doña Pomposa siempre espera ser cosa grande, título de Castilla cuando menos, a favor del poder de su belleza (p. 167). Lizardi, al parecer, exagera las ambiciones políticas de Don Quijote en su afán por satirizar, una vez más, el sueño español de la nobleza con tierras y títulos ganados a través de la conquista. A juzgar por el profundo sentimiento de Pomposa, que se siente insultada por el sobrenombre, la inmortal figura de Cervantes sólo proyecta un significado peyorativo de disparate pretensioso (p. 172). Es en este sentido que lizardi menciona a Cervantes como uno de los principales satiristas de las letras españolas, junto a Iriarte, Feijoo, Francisco Santos, Quevedo y Torres Villarroel y al Gil Blas ${ }^{24}$. Los cuatro últimos nombres señalan que Lizardi entiende el término "satírico" como muy relacionado con las obras picarescas. Al mencionar a Cervantes entre ellos, Lizardi no percibe la compasión humana del novelista por Don Quijote y Sancho Panza --caracterizaciones que trascienden el tipo satírico, aunque haya algo de parodia.

La frecuente comparación de personajes con un Don Quijote ridícu-

21 Véase Luis Cabrera, Diccionario de aztequismos, México, 1975, p. 25

${ }^{22}$ Periódicos, Obras, t. 5, UNAM, México, 1973, p. 286

${ }^{23}$ Ibid., p. 181.

${ }^{24}$ El Pensador Mexicano, p. 70. 
lo es sólo uno de los elementos cervantinos en la obra de Lizardi. Hay referencias de paso a otros nombres tomados del Quijote, incluyendo el yelmo de Mambrino ${ }^{25}$ como símbolo de la ilusión y la cueva de Montesinos como el lugar para los muertos inmortales en donde Lizardi satíricamente entierra un periódico rival que acaba de quebrar ${ }^{26}$.

En una evocación de Cervantes, el padre del Periquillo comenta que la inmortalidad del Quijote no salvó al autor de la dura crítica a su poesía, que ha sido prácticamente olvidada ${ }^{27}$. Lizardi debe haberse identificado con Cervantes, porque aunque el Periquillo le dio reconocimiento inmediato, sus versos satíricos tuvieron pobre acogida de la crítica de su época; fue considerado, en este aspecto, un pobre imitador de Quevedo ${ }^{28}$. Por lo tanto, la evocación de Cervantes sugiere cierta simpatía autobiográfica.

Se pueden mencionar técnicas literarias comunes en el Quijote y las novelas de Lizardi: hay cinco cuentos intercalados en el Periquillo y otros tantos en La Quijotita, a menudo sin relación alguna con el argumento principal de la historia, aunque algunos son remembranzas de historias de personajes secundarios, igual que, en ocasiones, en el Quijote ("La historia del cautivo"). Los títulos de los capítulos del Periquillo recuerdan los del Quijote pues resumen los argumentos principales y terminan con un apéndice atractivo como por ejemplo: "con otras cosas de mucho gusto y pasatiempo" (Quijote II, p. 1089) ${ }^{29}$; "con otras cosas deleitables y pasaderas" (Periquillo, p. 471); "con otras aventuras dignas de contarse" (Quijote II, p. 1088); “con otras aventuras curiosas" (Periquillo, p. 47); “que las sabrá quien las leyere, si las lee con atención” (Quijote II, p. 1093); “pero es menester leerlas para saberlas" (Periquillo, p. 471).

Así como Cervantes, Lizardi usa los títulos de los capítulos a modo de señuelos para el lector: aquél está más obsesionado con las "venturas dignas de ser contadas", éste es más humilde con sus diminutivos y dobles negaciones típicamente mexicanas (por ejemplo, "con otras cosillas no del todo despreciables" 30 . Sin embargo, ambos están preocupados de no subvalorar "esta verdadera historia", frase usada por el español y el mexicano ${ }^{31}$.

Las últimas líneas de muchos capítulos en las novelas de Lizardi también son cervantinas en tanto que incitan al lector a continuar en el siguiente capítulo: "comenzó a decir lo que oirá y verá el que le oyere o viere el capítulo siguiente" (Quijote II, p. 728). "En uno de estos tuve un encuentro con un maldito viejo, y por poco me pierdo, como

25 El Periquillo, p. 200.

26 Segunda carta del Pensador al Payo del Rosario: Muerte y funeral del Centzontli, Imprenta de M. Ontiveros, México, 1824, p. 7.

27 El Periquillo, p. 67.

28 SPELL, The life and works, p. 60.

29 Utilizo la edición de Martín de Riquer, Barcelona, 1967.

30 El Periquillo, p. 470.

31 Ibid., p. 472; Don Catrin, p. 144; Don Quijote, II, p. 1088. 
verá el que leyere lo que sigue" (Don Catrín, p. 144). Esta técnica usada ocasional y acertadamente por Cervantes, se convierte en un cliché demasiado usado en las tres novelas de Lizardi. De hecho, el lector se aburre de leer "como veréis en el capítulo siguiente".

Uno de los efectos buscados en las historias interrumpidas, tanto en el Periquillo como en el Quijote, es el suspenso. Periquillo está escuchando la historia (interpolada) de su compañero de prisión, Antonio Sánchez, cuando los gritos de los guardias de la prisión interrumpen el hilo de la historia, el cual se recogerá y terminará en el siguiente capítulo ${ }^{32}$, caso muy similar al del "Curioso impertinente" cervantino. Pero Lizardi no es tan eficaz en el recurso de la historia suspendida. Es más, el efecto cervantino de una realidad (Don Quijote) que irrumpe en otra es más barroco y complejo que las memorias interrumpidas de Antonio Sánchez. Don Quijote emerge más como un ser humano de carne y hueso contra el telón de fondo de la historia desordenada del "Curioso impertinente". Antonio Sánchez y Periquillo no consiguen verosimilitud, especialmente porque el primero está involucrado en ambos niveles de la narración.

En dos escenas de combate interrumpido se busca igualmente la parodia de suspenso: Don Quijote y Vizcaíno se enfrentan a punta de espada al final de la Primera parte del Quijote, de la misma manera que Tremendo y Modesto quedan congelados con los sables en alto al final de un capítulo de Don Catrín. El paralelo se completa con el hecho de que ambas contiendas llegan a su clímax al principio del siguiente capítulo, aunque la interrupción tiene, obviamente, causas diferentes. El narrador del Quijote tuvo que localizar y mandar traducir las páginas perdidas del manuscrito de Cide Hamete Benengeli. El narrador autobiográfico, Don Catrín, simplemente siente que debe tomar un descanso: "pues este ya va muy largo y el prudente lector tendrá ganas de fumar, de tomar un polvo, toser o estornudar, y no será razón impedirle que tome un poco de resuello"33. El efecto del suspenso es cómico en ambos: en Cervantes, la búsqueda de las páginas perdidas es tan una burla-seria que resulta absurda en sus detalles, parodia de un recurso muy gastado de las novelas de caballerías ${ }^{34}$. En Lizardi, el rompimiento es tan inconsecuente que también es absurdo.

Así como el narrador cervantino arma el manuscrito de Cide Hamete "El Pensador" (seudónimo de Lizardi) aparece al final del Periquillo con el manuscrito de su autobiografía. Ambos realizan tareas similares como editores, comentaristas y críticos de los manuscritos desorganizados que tienen en las manos ${ }^{35}$, pero este papel, complejo, sutil y ambiguo dadas las tres perspectivas que intervienen intermitentemente para comentar el Quijote, en la novela de Lizardi es elemental,

32 El Periquillo, pp. 164, 174.

33 Don Catrin, p. 37.

34 E. C. Riley, op. cit., p. 205.

35 Don Quijote, I, pp. 90-93; II, p. 713, pp. 848-849; El Periquillo, pp. 462-464. 
ya que "El Pensador" actúa como portavoz de Lizardi únicamente al final.

En Don Catrin de la Fachenda, aparece también un editor, el practicante del hospital -que debe poner triste final al cuaderno autobiográfico de Don Catrín-, que evita la crítica y se mantiene en el papel de moralista cuando dice " ¡Pobre Catrín! iOjalá no tenga imitadores!" (p. 153). Aparentemente, Lizardi quiere asegurarse de que el lector no cerrará el libro cautivado por el encanto de las palabras del autor. El título original, abreviado en las ediciones modernas, Vida y hechos del famoso caballero Don Catrín de la Fachenda, sugiere la parodia del título original de la segunda parte de la obra de Cervantes -El Ingenioso caballero Don Quijote de la Mancha ${ }^{36}$ - en la secuencia de los sonidos, y en el significado cómico de palabras como quijote y mancha, paralelas a catrin y fachenda. Como Don Quijote, Don Catrín está muy consciente desde el principio de la novela de que será famoso en todo el mundo cuando se publique su historia ${ }^{37}$. La hipérbole de la fama consciente de Don Catrín es parodia de su vanidad como hidalgo, mientras que Don Quijote tiene la oportunidad de observar no sólo el impacto de la primera parte de su historia, sino también la del volumen de Avellaneda ${ }^{38}$. En Don Catrín Lizardi muestra preocupación por la crítica de su novela anterior, el Periquillo (incluyendo "las digresiones fastidiosas"), tal como Cervantes en la segunda parte trata de responder a la crítica de las historias interpoladas que se encuentran en la primera parte ${ }^{39}$. Como sus protagonistas, ambos autores están muy conscientes de su reputación conseguida en obras anteriores.

Si Don Quijote es la parodia del caballero andante, Don Catrín se auto-satiriza revelando su naturaleza picaresca al tiempo que presume de ser un caballero colonial ('hombre con sangre noble española'). Sin embargo, la parodia como forma suprema de la imitación literaria falta en las novelas de Lizardi, excepto quizá en La Quijotita y su prima. Cuando muere Pamela, el perro de Quijotita (nombre sugerido por el título de la novela sentimental de Samuel Richardson que había afectado a la Quijotita), el epitafio se pone en latín, y el "juguetillo satírico" --dice el pie de página de Lizardi- es una burla de los garabatos del "doctor don José María Guridi y Alcocer" (p. 193). Contemporáneo de Lizardi fue un sacerdote y teólogo llamado José Miguel Guridi y Alcocer que participó en la política pro-independentista y escribió un tomo titulado Arte de la lengua latina ${ }^{40}$, del cual Lizardi sacó probablemente la idea de satirizar la predilección por el latín

36 MARTIN DE RIQUER, Aproximación al Quijote, España, 1971, p. 41.

37 Don Catrin, p. 4; Don Quijote, I, p. 42.

38 Don Quijote, II, p. 556, pp. 1053-1054.

39 Don Catrin, p. 4; Don Quijote, II, p. 848.

40 Diccionario Porrúa de historia. Biografía y Geografía de México, 4a ed. t. 1, México, 1976, pp. 953-954. 
entre los académicos de la Iglesia. Lizardi no sólo parodia el estilo del eclesiástico mexicano, sino que imita a "los académicos de Argamasilla" cervantinos que escriben epitafios en verso para los personajes principales de la novela incluyendo a Rocinante.

Los prólogos de ambas novelas, ingeniosos en la forma, establecen los propósitos de las obras: Cervantes aclara que su obra es "una invectiva contra los libros de caballerías" (I, p. 24), Lizardi repite en sus diferentes prólogos que el propósito de la obra es enseñar a los hijos del Periquillo las lecciones que él aprendió sobre los vicios y las virtudes en la vida (pp. 5, 7). Ambos novelistas apelan a recursos narrativos a través de diálogos entre amigos que discuten los problemas claves que confronta el narrador. En el Quijote, la cuestión es si el narrador debe empezar con una demostración tradicional de erudición (las Sagradas Escrituras, los clásicos). La cuestión central del diálogo en el Periquillo es a quién debe dedicar "El Pensador" su libro. Lizardi sigue la tradición al citar a los autores clásicos (Ovidio, Horacio y Marcial, y media docena más), pero abre nuevos caminos al dedicar su libro a sus lectores, por muy plebeyos que sean algunos, en lugar de la tradicional dedicatoria a un noble mecenas (al que debe suscribirse Cervantes) puesto que no lo tiene. Lizardi debe confiar en la venta de sus libros para mantenerse, y es honesto al admitirlo. Tanto Cervantes como Lizardi establecen contacto con el lector desde el principio. El español lo hace con una circunspección cortés a su "desocupado lector", a quien atribuye libre albedrío para hacer comentarios favorables o desfavorables sobre la novela ( $\mathrm{L}$ p. 19). Lizardi está más a la defensiva. Dedicará el libro a sus lectores plebeyos "aunque me critiquéis de arriba abajo, y aunque hagáis cartuchos o servilletas con los libros" (p. 4). Lo importante en esos prólogos es el diálogo aparente con el lector invitándole a proceder en forma familiar en la obra, como si la lectura fuera la continuación de una conversación entre amigos íntimos.

No cabe la menor duda de que Lizardi en su prólogo al segundo volumen del Periquillo imita muy de cerca el significado y la forma de la dedicatoria y el prólogo de la segunda parte del Quijote. Cada autor revela su amarga obsesión con la crítica al primer volumen de su novela. Cervantes admite sentir náuseas con la secuela apócrifa de Avellaneda al Quijote, y se siente especialmente molesto con el retrato calumnioso de su novela en esa obra. Para fastidiar y denigrar a Avellaneda, cuenta dos historias llenas de humor vulgar. En paralelo simbólico, Avellaneda es como el loco de Sevilla que cree ha realizado una gran hazaña al mutilar a un perro (o al imitar una novela), así que presume: "¿Pensarán vuestras mercedes ahora que es poco trabajo hacer un libro?” (II, p. 537). También con un diálogo Lizardi se venga de las "murmuraciones" (porque no pueden llamarse críticas; p. 189) y, como Cervantes, repite parte de la crítica: "Dicen que este Perico habla más que lo que se necesita;...que a título de crítica es un murmu- 
rador eterno de las clases y las corporaciones del Estado" (p. 188) e inserta un dicho realista: "es más fácil que un panal se libre de la golosina de un muchacho, que la obra más sublime del agudo colmillo del zoylo" (p. 187). Mientras que Cervantes demuestra en su segundo prólogo una afinidad para las historias vulgares con el tono de la tradición oral, Lizardi revela que las fábulas están más cerca de su alma literaria. En repetidas ocasiones cita las fábulas de Iriarte, y da el nombre alegórico de Conocimiento al amigo que participa en el diálogo del segundo prólogo.

Hay en esas dedicatorias y prólogos una abierta preocupación por el dinero, y un conocimiento de que puede haber un público lector de diferente estrato social. Lo que en Cervantes es sólo una insinuación ("lector ilustre o quier plebeyo") en Lizardi se convierte en obsesión. El "yo" narrador en el prólogo lizardiano insiste en que no quiere "un sinnúmero de lectores, ni apetezco los vítores de la plebe ignorante y novelera. Me contento con pocos lectores, que siendo sabios no me haría daño su aprobación" (p. 188). Pronto contradice su actitud elitista con la ironía picaresca arraigada en la ambición: "Es verdad que apetecería tener no ya muchos lectores sino muchos compradores". El rápido giro en su actitud es convincente al retratar las pasiones contradictorias de un escritor orgulloso pero necesitado, y como tal es una caracterización verosímil. Aparentemente, la obsesión por obtener ganancias fue una de las acusaciones lanzadas a Lizardi por sus críticos. Cervantes muestra en la dedicatoria de la segunda parte una preocupación similar pero más es la búsqueda de un mecenas. Como respuesta a la sugerencia de que él buscaba patrocinio del Emperador de la China para convertirse en rector de la universidad de allí, Cervantes proclama orgullosamente: "estoy muy sin dineros, y emperador por emperador y monarca por monarca, en Nápoles tengo al grande Conde de Lemos, que, sin tantos titulillos de colegios ni rectorías me sustenta, me ampara y hace más merced que la que yo acierto a desear" (II, p. 534). Sin embargo, es como "pobre pero orgulloso" que Cervantes toma la amenaza de que la secuela apócrifa de Avellaneda pueda robarle sus beneficios: "la pobreza puede anular a la nobleza, pero no oscurecerla del todo" (II, p. 538). El miedo a la pobreza está ahí, mecenas o no mecenas.

Es evidente en todos estos paralelos que Lizardi imita a Cervantes en forma y tema. Ambos autores revelan no sólo una obsesión por sus críticos sino que hacen crítica literaria de sus novelas. Los comentarios de "El Pensador" al final del Periquillo se pueden tomar como la teoría de Lizardi sobre su novela. El estilo entretenido -. "un estilo casero y familiar", "los dicharachos y refranes del vulgo", "la chanza" (p. 463) - sirven de carnada para atraer a un público de lectores más vasto. Por esta razón el autor ha tenido que escribir "sin afectación ni pedantismo" (p. 11) aunque ostenta erudición a pesar de su declarada simplicidad. Entre los dos propósitos clásicos de la literatura como 
diversión y como instrucción, Lizardi cree sin duda que la didáctica es el fin, la diversión el medio.

En cuanto a la teoría de Cervantes sobre la novela según se manifiesta en el Quijote, acepto la hipótesis de E. C. Riley de que el canon de Toledo es lo más cercano a la opinión del autor ${ }^{41}$. El canon sigue el precepto de Horacio cuando insiste en que las mejores novelas "deleitan y enseñan juntamente" ${ }^{2}$. Sin embargo Cervantes señala que hay que divertir al lector a través de la tensión de la credibilidad: "Tan to la mentira es mejor cuando más parece verdadera y tanto más de lo dudoso y posible. Hanse de casar las fábulas mentirosas con el entendimiento de los que las leyeren, escribiéndose de suerte que, facilitando los imposibles, allanando las grandezas, suspendiendo los ánimos, admiren, suspendan, alborocen, y entretengan, de modo que anden a un mismo paso la admiración y la alegría juntas" (I, p. 482).

Si la verosimilitud que entretiene es la ideé fixe de Cervantes sobre la novela, la de Lizardi es la lección moral, quizá la mayor diferencia teórica entre el mexicano y el español.

La diferencia esencial entre Cervantes y Lizardi como críticos literarios se halla en el recuento de las bibliotecas de sus personajes, aunque estos episodios muestran que el Quijote sirve de modelo para el argumento de La Quijotita. Así como el cura echa al fuego los libros que considera sin valor de la biblioteca de Don Quijote, así Doña Eufrosina, la madre de Quijotita, arroja al fuego los libros a los cuales culpa de los excesos de su hija. La "locura" de la Quijotita es una forma de piedad exagerada, un idealismo espiritual trastornado, similar a la caballería de Don Quijote. ¿Qué libros sufren las llamas de esta inquisición? Todos los libros piadosos y alrededor de quinientas novenas, que contienen ejercicios de devoción y plegarias que se usan por períodos de nueve días cada una $^{43}$. Hay un solo criterio para la censura: los temas religiosos que han instruido perversamente a la Quijotia.

El escrutinio del cura destaca algunos criterios predominantes para el juicio. Se consideran cualidades positivas en la literatura el "grande artificio", "decoro", originalidad y sobre todo buen estilo. Se consideran malas la "dureza y sequedad de estilo", "impertinencias", "revueltas razones", y sobre todo los disparates (I, pp. 67-73). La verosimilitud es importante: Tirant lo Blanc merece alabanza porque en lugar de inventar "necedades de industria", describe con realismo a los caballeros andantes que comen, duermen y mueren en sus camas, "y hacen testamento antes de su muerte, con estas cosas de que todos los demás libros de este género carecen" (I, p. 72).

En La Quijotita, el coronel Don Rodrigo expresa las opiniones del

41 E. C. RILEY, op. cit., p. 182.

42 Don Quijote, I, p. 481.

43 La Quijotita, p. 245. 
propio Lizardi al recomendar a Doña Eufrosina una serie de tratados sobre la educación de las mujeres de autores como Fenelón, Blanchard y otros. Considera estas obras no de ficción sino como lecturas más apropiadas que las obras que se encuentran en su biblioteca ${ }^{44}$. Veamos si hay un común denominador en la supuesta inferioridad de esos libros. Primero, hay una alusión breve a las Novelas ejemplares y amorosas de María de Zayas. Están las "obras jocosas" de Francisco de Quevedo, refiriéndose a sus versos y prosa satíricos, a veces indecentes. Las Aventuras de Gil Blas de Santillana, de Lesage y traducidas por el padre Isla (Madrid, 1787), representa la novela picaresca, cortesana popular en el mundo español. Clara de Marie Cottin Risteau (1799), un éxito extraordinario en su época, es una obra de pasión violenta, muy parecida a la vida escandalosa de su autora que terminó suicidándose. Es sorprendente que un moralista como Lizardi incluya también en su lista de libros menos recomendados Pamela o la virtud recompensada, novela sentimental inglesa con moraleja (la sirvienta Pamela es recompensada por resistir los avances de su patrón casándose con él después; un final tan virtuoso debería haber complacido a Lizardi); sólo podemos concluir que el utilitarista mexicano se oponía a la lectura excesiva de obras de ficción populares y sentimentales -en este caso, probablemente la novela más leída del siglo.

También se encuentran en la biblioteca de doña Eufrosina dos obras famosas por sus descripciones líricas del amor y la naturaleza, no muy recomendadas por Don Rodrigo/Lizardi: Diana enamorada de Gil Polo (1564), novela en verso y prosa, y Atala (1801), la novela romántica de Chateaubriand cuyo subtítulo (Bellezas poéticas y morales de la religión cristiana) debió agradar a Lizardi, el moralista cristiano. Tal vez las descripciones eróticas llevaron a Lizardi a concluir que la novela provocaría una tentación indebida en las lectoras. La espiritualidad sin la castidad sería inaceptable para Lizardi. Así incluye en su lista de obras censuradas la de Cristóbal Lozano, Soledades de la vida y desengaños del mundo ${ }^{45}$, una serie llena de temas y sentimientos barrocos que también presagian el período romántico.

Hasta el momento encontramos un común denominador en los títulos de la lista menos recomendados por Lizardi: temas de pasión y romance de popularidad en esa época. Aflora el sentimiento misionero censor, puritano de Lizardi. Debe recordarse que la crítica aparece en forma de consejos que un hombre mayor da a una dama de la sociedad "respetable". Solamente a la luz de esta conclusión podemos

44 Véase Jefferson Rea Spell, The educational views of Fernández de Lizardi, pp. 259274, La Quijotita y su prima, pp. 47-49.

45 Madrid, por Francisco Sanz, 1662. Una edición de esta serie incluye novelas y obras de teatro con títulos tan amorosos como: Las Serafinas, El más mal pagado amor. Todo es trazas, Buscar su propia desdicha, Pasar mal por querer bien, El muerto celoso, Persecuciones de Lucinda, Los amantes portugueses, En mujer venganza honrosa, El estudiante de día y galán de noche. 
entender por qué incluye Lizardi, en su lista de libros menos recomendados, al Eusebio (1786-1788) de Montengón. Se esperaría que Lizardi aplaudiera el mensaje de Montengón sobre la necesidad de predicar las virtudes morales a la gente de todas las religiones, aceptaran o no los dogmas y ritos del catolicismo ${ }^{46}$. Eusebio es una obra pedagógica a imitación del Emilio de Rousseau, pero con un revisionismo cristiano del autor jesuita. Ciertamente, Lizardi podría estar de acuerdo con la crítica de Montengón a la educación hispánica tradicional ${ }^{47}$ o con su idea de "la necesidad que tiene un hombre, aunque noble, de aprender un oficio para asegurar su sustento honradamente contra todos los accidentes de la fortuna ${ }^{48}$. Eusebio era una de las novelas más populares de España en los siglos XVIII y XIX, especialmente porque la Inquisición la prohibió en 1799 por ser lasciva y demasiado tolerante, "permitiendo entre esposos de futuro cosas que sólo son lícitas a los casados, y, últimamente, presentando como un legítimo matrimonio lo que no es sino un verdadero amancebamiento entre un quaker y una católica"49. Probablemente Lizardi, el mojigato moralista, encontró este aspecto de Eusebio como el más reprobable de todos, y por lo tanto lo colocó en la lista de los libros no recomendables.

Otra novela popular que aparece en la lista es Don Quijote de la Mancha. Sorprende que la obra maestra de Cervantes se considere menos recomendable que, por ejemplo, Cartas sobre la educación de las niñas de Madame de Maintenon. Don Rodrigo/Lizardi mantiene sus recomendaciones aunque muchas de las novelas mencionadas puedan ser "divertidas"; algunas pueden ser mejores que otras (probablemente salvando así al Quijote del olvido), pero sus tratados pedágogicos instruirán mejor a Doña Eufrosina para ser una mujer casada y una madre: el criterio es didáctico no artístico, como lo muestran sus comentarios sobre el Emilio, cuyo valor está en sus ideas educativas más que por el talento de Rousseau como escritor ${ }^{50}$.

El hecho de que la inestable Quijotita tenga particular interés en leer muchas comedias y sainetes, antes de volverse una fanática religiosa, provoca un comentario de Lizardi cargado de desdén por el teatro (p. 49). Esta idea se desarrolla más en la conversación entre Pudenciana, la niña idealmente educada, y su padre. Él le aconseja que vea obras como La misantropia, que enseña la lección moral de los remordimientos sufridos por una mujer que ha sido infiel a su marido (p. 185), y no las obras que muestran a las jóvenes las artimañas

46 Eusebio, Imprenta del Colegio de Paluzie, Barcelona, 1842, t. 1, p. 7.

47 Eusebio, t. 4, p. 251.

48 Ibid., t. 1, p. 47.

49 Joaquín Rodríguez Arzúa, nota preliminar a Frioleras eruditas y curiosas de Pedro Montengón, Madrid, 1944, pp. 8-9.

so La Quijotita y su prima, p. 88. 
con las que las damas de comedias engañan a padres y esposos. Lizardi se parece más a Cervantes cuando censura aquellas comedias mágicas y comedias de títeres que son "insípidas, inverosímiles y fantásticas" llenas de sucesos increíbles que inducen una naturaleza supersticiosa en los lectores (p. 187). La crítica de Don Quijote a los títeres de maese Pedro y la censura del cura a las novelas de caballerías que ostentan excesos inverosímiles, no son muy diferentes de las aseveraciones de Lizardi sobre las comedias mágicas: "Todas son fruslerías, extravagancias, desaliños, trampantojos, y para decirlo de una vez ridiculeces y títeres, más propios para divertir muchachos que para hacer perder el tiempo a muchas gentes que parecen juiciosas e instruidas" (p. 186).

Lizardi, lleno de optimismo de la Ilustración, tiene fe en que el nivel del teatro puede elevarse a través de la educación: se puede enseñar a las masas a disfrutar el Otelo de Shakespeare. Lizardi incorporaría obras de gran mérito artístico si también ofrecieran "un trazo moral" como Otelo, o "un retazo crítico", como La comedia nueva o el café de Moratín que satiriza a L. F. Comella, autor español de obras de pacotilla (p. 187).

Lizardi trataba de infundir en sus lectores un nuevo respeto por el estudio de las ciencias y de los tratados serios, ya que las obras de ficción de la época, por bien escritas que estuvieran, no eran suficientes para educar al público para una sociedad mejor. El perezoso Don Catrín comenta a su tío que él considera inútil el estudio de las ciencias, que ya tiene una educación completa por haber leído varias obras de Cervantes (el Quijote y Viaje del Parnaso), obras clásicas de la llustración (una enciclopedia completa, más los ensayos de Feijoo, Teatro crítico universal), la popular Gil Blas, y otros libros incluyendo muchas comedias y entremeses. El tío contesta que Don Catrín ha leído "mucho y bueno" - respuesta irónica, ya que el sobrino sólo ha mencionado seis títulos-; lo que refleja la verdad de las opiniones de Lizardi es la amonestación del tío a Don Catrín por su falta de respeto a las ciencias ${ }^{51}$.

La urgente necesidad de enseñar más ciencia en las escuelas católicas se hace evidente en el Periquillo. Lizardi insiste en que Aristóteles ha dominado por demasiado tiempo como rector de las ciencias en el escolasticismo, a expensas de físicos mucho más modernos como Descartes, Newton y Muschembreck (p. 38). Se ha desperdiciado demasiado tiempo memorizando el latín de los breviarios y catecismos; no se ha dado el debido énfasis al estudio de los clásicos de la literatura latina -Virgilio, Juvenal, Tácito, Lucano (p. 35). En boca del ejemplar maestro que aconseja al Periquillo, Lizardi vuelve a recomendar algunos tratados pedagógicos, relativamente desconocidos, por encima de las novelas de moda de María de Zayas y Cristóbal Lozano. Lizardi

51 Don Catrin, pp. 18-19. 
censura hasta algunos textos clásicos de la literatura española que no se pueden atribuir a la fantasía romántica - La historia de Carlos Magno y de doce pares, traducción de las baladas francesas; y Guerras civiles de Granada, de Ginés Pérez de Hita, obra que inspiró a escritores como Sir Walter Scott, Chateaubriand y Washington Irving ${ }^{52}$.

Lizardi no recomienda ninguna de estas obras literarias tan populares en su época porque podría corromper a la juventud con pensamientos lascivos (una preocupación propia del moralista mexicano) o les llenarían la cabeza con "fábulas, valentías y patrañas ridículas" ${ }_{53}$ (como dice Cervantes de muchas novelas de caballerías). Muy parecida a la forma en que el sacerdote examina la biblioteca de Don Quijote, los críticos literarios en la novela de Lizardi evalúan una serie de libros con una escala que va desde "elogioso" hasta "censurado". Sin embargo, para Lizardi, hasta las mejores novelas merecen menos atención de la que reciben, como si monopolizaran al público lector a expensas de libros más útiles que podrían ayudar concretamente a mejorar la sociedad. La razón didáctica que empujó a José Joaquín Fernández de Lizardi a escribir novelas en una época en que la censura le había obligado a dejar de publicar sus escritos periodísticos es consistente con su propia crítica literaria de las obras de ficción en general.

JOHN SKIRIUS

University of California, Los Angeles.

52 Ibid., p. 27; GEORGE TYLER NORTHUP, An introduction to Spanish literature, $3 a$ ed, rev. y ampliada por N. B. Adams, Chicago-London, 1967, pp. 158-159.

53. El Periquillo, p. 27. 